\title{
Handy Formula for Calculating the Probability of Parentage Exclusion
}

To the Editor:

Ito et al. (1985) have presented general formulae for calculating the probability of parentage exclusion based on restriction fragment length polymorphisms. The results were, however, rather clumsy in terms of allele frequency $\left(p_{i}\right)=\left(p_{1}, \ldots, p_{m}\right)$ where mode of inheritance assumed to be codominant for $\mathrm{m}$ multiple alleles. This can be simplified, as first noted by Komatsu (1952), with a mathematical fact that any symmetric polynomial with respect to $\left(p_{i}\right)$ is also expressible in terms of the power-sum of $\left(p_{1}\right)$ alone as a polynomial. In general if the function $\left(P_{i j}\right)$ of allele frequency holds a symmetric relation $P_{i j}=P_{j 1}$, the following identity is always true:

$$
\sum_{i<j}^{m} P_{i j}=\frac{1}{2}\left(\sum_{i=1}^{m} \sum_{j=1}^{m} P_{1 j}-\sum_{i=1}^{m} P_{1 j}\right)
$$

If $P_{i j}$ is not symmetric, then the quantity $P_{i j}+P_{j i}$, which is always symmetric, can be applied instead.

For example, since summand of the first term of right hand of the probability of parentage exclusion in case of an $\mathrm{X}$-linked locus with $\mathrm{m}$ codominant alleles, that is, $P_{i j}=p_{i} p_{j}\left(p_{i}+p_{j}\right)\left(1-p_{i}-p_{j}\right)$ is symmetric, we have

$$
\sum_{i<j}^{m} P_{1 j}=\frac{1}{2}\left\{\sum_{i=1}^{m} \sum_{j=1}^{m} p_{i} p_{j}\left(p_{1}+p_{j}\right)\left(1-p_{i}-p_{j}\right)-\sum_{i=1}^{m} 2 p_{i}^{3}\left(1-2 p_{i}\right)\right\}=S_{2}-S_{3}-S_{2}^{2},
$$

where $S_{k} \equiv S_{k}(m)=\sum_{i=1}^{m} p_{i}{ }^{k}$ or the $k$-th power-sum of $m$ allele frequency. Since the

Table 1. The probability of parentage exclusion in codominant and ABO-like systems.

\begin{tabular}{ll}
\hline Inheritance & \multicolumn{1}{c}{ Probability of parentage exclusion } \\
\hline Autosome & $: P A(m)=1-2 S_{2}+S_{3}-2 S_{2}{ }^{2}+2 S_{4}+3 S_{2} S_{3}-3 S_{5}{ }^{2}$ \\
X-linked & $: \mathrm{PS}_{\mathbf{X}}(\mathrm{m})=1 / 2\left(1-\mathrm{S}_{2}-\mathrm{S}_{2}{ }^{2}+\mathrm{S}_{4}\right)$ \\
Y-linked & $: \mathrm{PS}_{\mathrm{y}}(\mathrm{m})=1 / 2\left(1-\mathrm{S}_{2}\right)$ \\
Pseudoautosomal & $: \mathrm{PS}_{\mathrm{XY}}(\mathrm{m})=1-\mathrm{S}_{2}-1 / 2\left(\mathrm{~S}_{2}{ }^{2}-\mathrm{S}_{4}\right)$ \\
Mitochondrial & $: \mathrm{PS}_{\mathrm{M}}(\mathrm{m})=1-\mathrm{S}_{2}$ \\
ABO-like & $: \mathrm{P}(\mathrm{m})=\mathrm{PA}(\mathrm{m}-1)-\left(\mathrm{T}_{2}{ }^{2}-\mathrm{T}_{4}\right)-\mathrm{r}\left\{\mathrm{r}(2-\mathrm{r})+\left(4-\mathrm{r}-\mathrm{r}^{2}\right) \mathrm{T}_{2}-2(1+\mathrm{r}) \mathrm{T}_{3}-2 \mathrm{~T}_{4}+\mathrm{T}_{2}{ }^{2}\right\}$ \\
\hline
\end{tabular}

a After Komatsu (1952). $S_{k} \equiv S_{k}(m)=\sum_{i=1}^{m} p_{1}{ }^{k}, T_{k} \equiv S_{k}(m-1), p_{1}=$ frequency of the i-th allele, $\mathrm{m}=$ number of codominant allele, $\mathrm{r}=$ recessive allele in ABO-like system. 
remaining term of the probability will be $1-2 S_{2}+2 S_{3}-S_{4}$, the final result becomes $\mathrm{PS}_{\mathrm{x}}=\frac{1}{2}\left(1-\mathrm{S}_{2}-\mathrm{S}_{2}{ }^{2}+\mathrm{S}_{4}\right)$.

Handy formulae for the probability of parentage exclusion appeared in restriction fragment length polymorphisms are shown in Table 1 . Thus, it is simple enough to calculate the probability of parentage exclusion when the power-sums up to the fifth degree of $\mathrm{m}$ codominant allele frequency were computed by a desk calculator. Some inequalities discussed in Ito et al. (1985) are now very obvious with Schwartz inequality. Presence of recessive allele might create some complications, but the identity (1) can apply any symmetric function of gene frequency as illustrated in ABOlike system, for which a simplified formula was also given in Table 1.

\section{References}

Ito, H., Yasuda, N., and Matsumoto, M. 1985. The probability of parentage exclusion based on restriction fragment length polymorphisms. Jpn. J. Human Genet. 30: 261-269.

Komatsu, Y. 1952. Probablistic-theoretic investigations on inheritance. VII. Non-paternity problems. Proc. Jpn. Acad. 28: 102-125.

Norikazu Yasuda, Ph.D. Division of Genetics, National Institute of Radiological Sciences, Chiba 260, Japan

(Received April 24, 1986) 